\title{
IMPLEMENTASI MULTIMEDIA DEVELOPMENT LIFE CYCLE PADA APLIKASI MEDIA PEMBELAJARAN UNTUK ANAK TUNAGRAHITA
}

\author{
PUTRI AMBARWATI ${ }^{1}$, PUTRI SYIFA DARMAWEL 2 \\ Universitas Gunadarma12 \\ Putriambar16@gmail.com ${ }^{1}$ \\ Putrisyifad@gmail.com²
}

\begin{abstract}
Mental retardation is a condition of intellectual disabilities experienced by children who have abilities below average. Children with intellectual disabilities are difficult to understand the lesson because they have a delay in developing intelligence. Interactive multimedia-based learning media can be used as one solution to become a method in mentally disabled children's learning process. This study aims to build a learning media for mentally disabled children based on interactive multimedia called Edinata, which stands for learning media for children with intellectual disabilities. Edinata is an application to help developmentally disabled children in introducing letters, numbers, surrounding objects, and coloring games. The method used in the development of this interactive multimedia learning media is the Multimedia Development Life Cycle (MDLC), which consists of 6 stages: concept, design, material collecting, assembly, testing, and distribution. In this study, the black box method is used to conduct testing. Based on black-box testing that has been done, all the menus contained in the application can be run properly.
\end{abstract}

Key Words : mental retardation, interactive learning media

\begin{abstract}
ABSTRAK
Tunagrahita merupakan suatu kondisi keterbelakangan mental yang dialami oleh anak yang memiliki kemampuan dibawah rata-rata. Anak tunagrahita sulit untuk menangkap pelajaran karena memiliki keterlambatan dalam perkembangan kecerdasannya. Media pembelajaran berbasis multimedia interaktif dapat dijadikan salah satu solusi untuk dijadikan metode dalam proses pembelajaran anak tunagrahita. Penelitian ini bertujuan untuk membangun sebuah media pembelajaran untuk anak tunagrahita berbasis multimedia interaktif yang dinamakan dengan Edinata yang merupakan singkatan dari media pembelajaran untuk anak tunagrahita. Edinata merupakan sebuah aplikasi untuk membantu anak tunagrahita dalam pengenalan huruf, angka, benda sekitar, dan game mewarnai. Metode yang digunakan dalam pengembangan media pembelajaran multimedia interaktif ini yaitu Multimedia Development Life Cycle (MDLC) yang terdiri dari 6 tahapan yaitu konsep, perancangan, pengumpukan bahan, pembuatan, pengujian, dan distribusi. Pada penelitian ini digunakan metode black box untuk melakukan pengujian. Berdasarkan pengujian black box yang telah dilakukan, semua menu yang terdapat pada aplikasi dapat dijalankan dengan baik.
\end{abstract}

Kata Kunci: multimedia interaktif, tunagrahita 


\section{PENDAHULUAN}

Tunagrahita adalah istilah yang digunakan untuk menyebut anak yang mempunyai tingkat intelektual di bawah rata rata yaitu IQ $\leq 70$ [1]. Anak tunagrahita memerlukan bantuan atau layanan secara spesifik termasuk dalam pendidikannya. Ingatan dan perhatian anak tunagrahita lemah, tidak mampu memperhatikan sesuatu hal dengan serius dan lama, perhatian anak tunagrahita akan sering berpindah pada persoalan lain dalam waktu sekejap, apalagi dalam hal memperhatikan pelajaran, anak tunagrahita akan cepat merasa bosan [2].

Meskipun memiliki keterbatasan, setiap anak berhak untuk memperoleh pendidikan tak terkecuali kepada anak - anak tunagrahita. Berbeda dengan anak pada umumnya, anak tunagrahita cenderung sulit untuk menangkap pelajaran karena memiliki keterlambatan dalam perkembangan kecerdasannya. Oleh karena itu penting untuk mengidentifikasi keterbatasan anak tunagrahita, sehingga guru dan orang tua dapat memilih media pembelajaran yang sesuai dengan kebutuhan anak tunagrahita. Media pembelajaran tersebut harus menyenangkan, menarik dan mudah dipahami agar anak tunagrahita tidak cepat bosan dan teralihkan perhatiannya.

Seiring berkembangnya zaman, perkembangan teknologi juga semakin meningkat. Dalam upaya memanfaatkan teknologi, jenis media pembelajaran saat ini semakin beragam. Salah satunya adalah dengan menggunakan multimedia interaktif. Penggunaan multimedia interaktif dapat meningkatkan hasil belajar siswa pada anak tunagrahita ringan [3]. Melalui media pembelajaran interaktif dapat pula membantu guru dalam meningkatkan keaktifan dan pemahaman siswa tunagrahita.

Salah satu perangkat lunak yang dapat membuat multimedia interaktif adalah perangkat lunak adobe flash. Adobe Flash merupakan program animasi yang juga mendukung pemrograman dengan Action script, program ini tepat digunakan untuk mengembangkan MPI (Multimedia Pembelajaran Interaktif) karena mendukung animasi, gambar, image, teks \& pemrograman [4], sehingga media tersebut diharapkan sesuai dengan karakter anak tunagrahita, materi yang mudah dipahami dan bersifat konkrit. Terdapat bukti yang menunjukkan bahwa pembelajaran dengan aplikasi game adobe flash dalam komputer dengan menggunakan software adobe flash diterima dengan baik oleh siswa tunagrahita dan memberikan potensi yang besar untuk mereka dalam pembelajaran matematika [5].

Tentunya, dalam membangun media pembelajaran berbasis multimedia interaktif membutuhkan metode pengembangan perangkat lunak yang sesuai agar dapat berjalan optimal. Perangkat lunak multimedia mempunyai karakterisitik yang berbeda dengan perangkat lunak klasik [6]. Hal ini disebabkan multimedia merupakan kombinasi dari elemen teks, gambar diam/foto/seni grafis, suara, animasi, dan video yang dimanipulasi secara digital. Metode yang sesuai untuk pengembangan multimedia interaktif yang dapat digunakan salah satunya adalah metode Multimedia Development Life Cycle (MDLC).

Berdasarkan hal tersebut, peneliti membuat suatu aplikasi berupa media pembelajaran multimedia interaktif untuk anak tunagrahita ringan menggunakan model proses Multimedia Development Life Cycle (MDLC). Aplikasi ini merupakan sebuah media pembelajaran yang di dalamnya terdapat edukasi tentang mengenal huruf, mengenal angka dan berhitung, mengenal benda, dan memiliki menu game edukasi yang berupa mewarnai. Aplikasi ini dibuat untuk edukasi anak tunagrahita dengan klasifikasi ringan agar dapat belajar membaca, menulis, berhitung sederhana dan mengenal benda-benda di sekitarnya.

\section{TINJAUAN PUSTAKA}

\section{Tunagrahita}

Tunagrahita adalah salah satu jenis mental retradation yaitu kondisi khusus di mana anak memiliki keterbelakangan dalam intelegensi, fisik, emosional, sosial yang membutuhkan perlakuan khusus supaya dapat berkembang pada kemampuan yang maksimal [7]. Kemampuan intelektual dibawah rata-rata yang dimiliki oleh anak tunagrahita menyebabkan mereka lamban dalam mempelajari hal baru dan mengerjakan tugas-tugas sederhana, kesulitan dalam mempelajari dengan kemampuan abstrak, serta mudah lupa dengan apa yang baru saja dipelajari kecuali jika latihan terus menerus [8]. Anak tunagrahita dapat dikelompokan menjadi beberapa bagian seperti ringan, sedang, dan berat [9]. Berikut merupakan klasifikasi anak tunagrahita berdasarkan IQ-nya [10] :

- Tunagrahita Ringan (IQ: 50-70)

- Tunagrahita Sedang (IQ: 30-50)

- Tunagrahita Berat (IQ: kurang dari 30)

\section{Multimedia Pembelajaran Interaktif}

Multimedia interaktif adalah suatu media yang dilengkapi dengan alat pengontrol yang dapat dioperasikan oleh pengguna sehingga pengguna dapat memilih apa yang dikehendaki untuk proses selanjutnya seperti pembelajaran interaktif dan aplikasi permainan, sedangkan pembelajaran diartikan sebagai proses penciptaan lingkungan yang memungkinkan terjadinya proses belajar [11]. Proses multimedia learning bisa dipandang sebagai akusisi informasi (pesan-pesan multimedia adalah kendaraan pengirim informasi) atau sebagai instruksi pengetahuan (pesan-pesan multimedia adalah alat bantu untuk menciptakan penalaran). Salah satu tujuan pembelajaran dengan multimedia inter- 
aktif adalah sebisa mungkin dapat menggantikan atau melengkapi serta mendukung unsur-unsur seperti tujuan materi, metode, dan alat penilaian yang ada dalam proses belajar mengajar dalam sistem pendidikan konvensional [12].

\section{Multimedia Development Life Cycle}

Metode Luther merupakan metode pengembangan perangkat lunak multimedia dimana metode yang digunakan dalam pengembangan multimedia ini adalah Multimedia Development Life Cycle yang terdiri dari enam tahap yaitu concept (pengonsepan), design (perancangan), material collecting (pengumpulan materi), assembly (pembuatan), testing (pengujian), dan distribution (pendistribusian) [13] .

\section{Black box Testing}

Black box Testing merupakan jenis pengujian perangkat lunak dari segi spesifikasi fungsional tanpa menguji desain dan kode program [14]. Terdapat beberapa kelebihan dalam melakukan pengujian black box [15]:

- Jumlah test case dapat dikurangi untuk mencapai pengujian yang wajar

- Test case dapat menunjukkan ada atau tidaknya kesalahan.

- Penguji tidak harus tahu coding.

- Programmer dan penguji keduanya independen satu sama lain.

- Lebih efektif daripada white box testing pada source code yang panjang.

\section{METODE}

Penelitian ini menggunakan metode penelitian studi pustaka. Metode penelitian studi pustaka yaitu dengan mencari literatur bacaan serta sumber referensi yang mendukung dan berkaitan dengan topik penelitian sebagai landasan teoritis yang akurat. Penelitian ini menggunakan Multimedia Development Life Cycle sebagai metode pengembangan perangkat lunak yang digunakan.

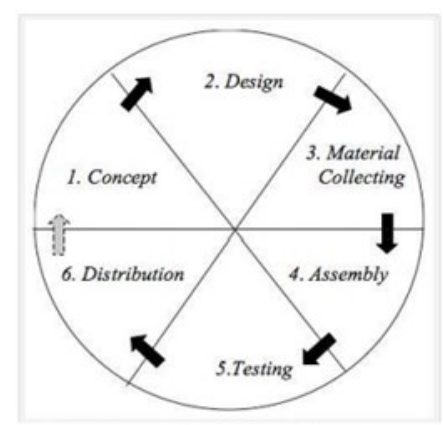

Gambar 1. Multimedia Development Life Cycle
Berikut ini adalah tahapan dari Multimedia Development Life Cycle:

\section{a. Concept}

Tahap concept (konsep) adalah tahap untuk menentukan tujuan dan siapa pengguna program (identifikasi audience). Selain itu menentukan macam aplikasi (presentasi, interaktif, dII) dan tujuan aplikasi (hiburan, pelatihan, pembelajaran, dII).

\section{b. Design}

Design (perancangan) adalah tahap membuat spesifikasi mengenai arsitektur program, gaya, tampilan dan kebutuhan material/bahan untuk program.

\section{c. Material collecting}

Material collecting adalah tahap dimana pengumpulan bahan yang sesuai dengan kebutuhan dilakukan. Tahap ini dapat dikerjakan paralel dengan tahap assembly. Pada beberap kasus, tahap material collecting dan tahap assembly akan dikerjakan secara linear tidak paralel.

\section{d. Assembly}

Tahap assembly (pembuatan) adalah tahap dimana semua objek atau bahan multimedia dibuat. Pembuatan aplikasi didasarkan pada tahap design.

\section{e. Testing}

Testing dilakukan setelah selesai tahap pembuatan (assembly) dengan menjalankan aplikasi atau program dan dilihat apakah ada kesalahan atau tidak. Tahap ini disebut juga sebagai tahap pengujian alpha (alpha test) dimana pengujian dilakukan oleh pembuat atau lingkungan pembuatnya sendiri.

\section{f. Distribution}

Tahapan dimana aplikasi disimpan dalam suatu media penyimpanan. Pada tahap ini jika media penyimpanan tidak cukup untuk menampung aplikasinya, maka dilakukan kompresi terhadap aplikasi tersebut. 


\section{HASIL DAN PEMBAHASAN}

\section{Konsep (Concept)}

Aplikasi ini memiliki konsep sebagai media pembelajaran untuk anak tunagrahita atau yang bisa disingkat menjadi Edinata. Aplikasi Edinata berisi pembelajaran mengenai pengenalan huruf, angka, dan benda benda sekitar yang interaktif, menyenangkan, dan mudah digunakan. Aplikasi ini juga disertai latihan dengan konsep permainan agar anak tunagrahita tidak cepat bosan. Pengguna aplikasi ini adalah untuk anak tunagrahita ringan. Namun, tidak menutup kemungkinan bahwa anak dengan tunagrahita sedang juga bisa menggunakannya. Diharapkan aplikasi ini dapat menjadi media pembelajaran yang bermanfaat bagi anak tunagrahita khususnya dalam kategori ringan dalam proses pembelajaran pengenalan huruf, angka, dan benda-benda sekitar.

\section{Perancangan (Design)}

Rancangan penelitian ini menggunakan struktur navigasi dan mockup sebagai gambaran aplikasi.

\section{a. Struktur Navigasi}

Berikut merupakan struktur navigasi dari Aplikasi Edinata:

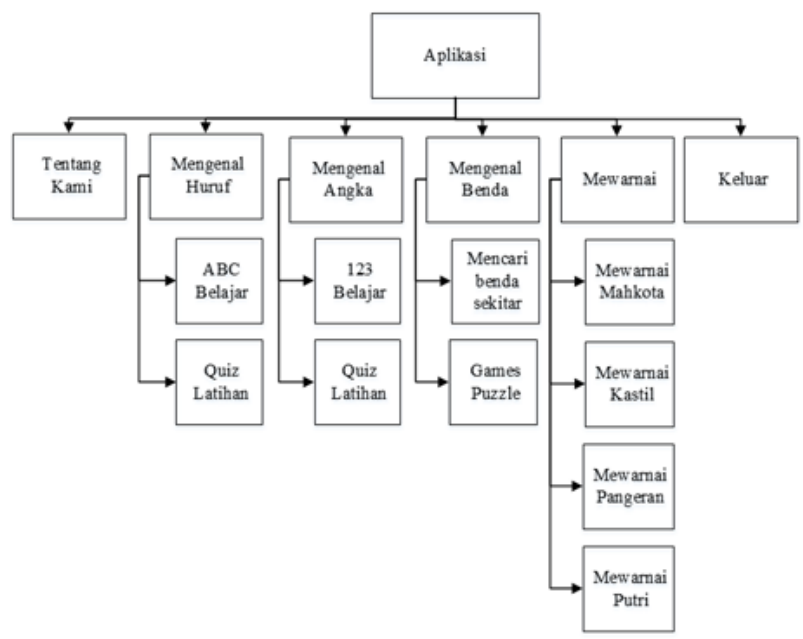

Gambar 2. Struktur Navigasi

\section{b. Mockup}

Perancangan dibuat dengan menggunakan mockup pada halaman utama dan setiap menu-menu yang terdapat pada Aplikasi Edinata. Berikut merupakan desain tampilan mockup pada media pembelajaran untuk anak tunagrahita atau Aplikasi Edinata.

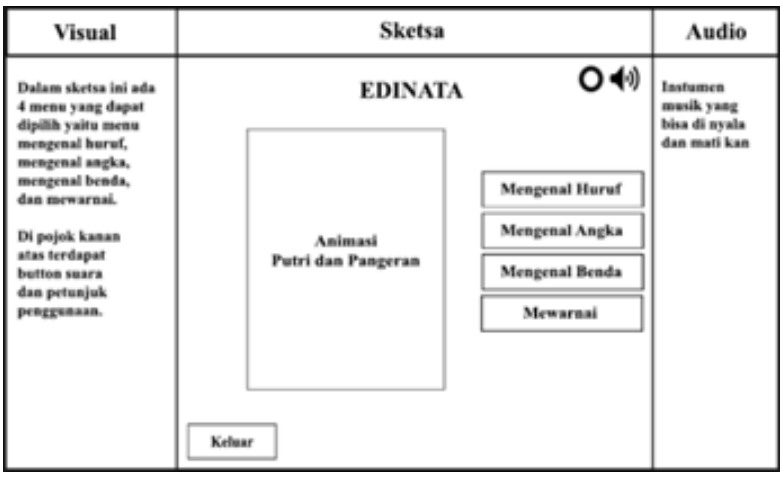

Gambar 3. Desain Halaman Utama

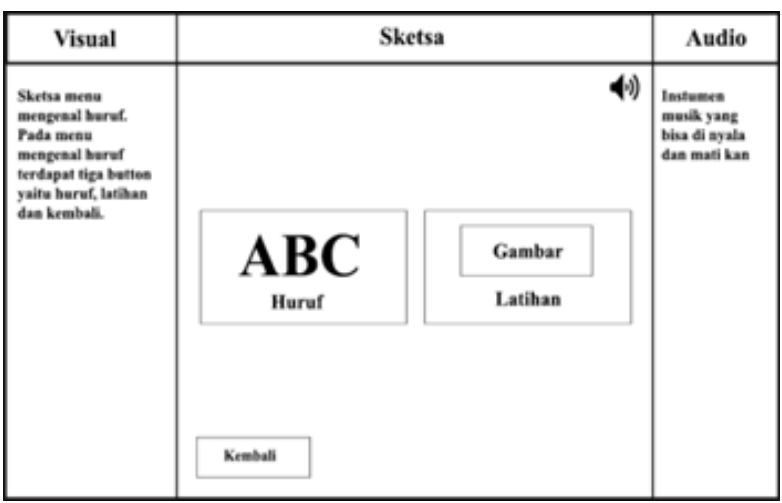

Gambar 4. Desain Halaman Menu Mengenal Huruf

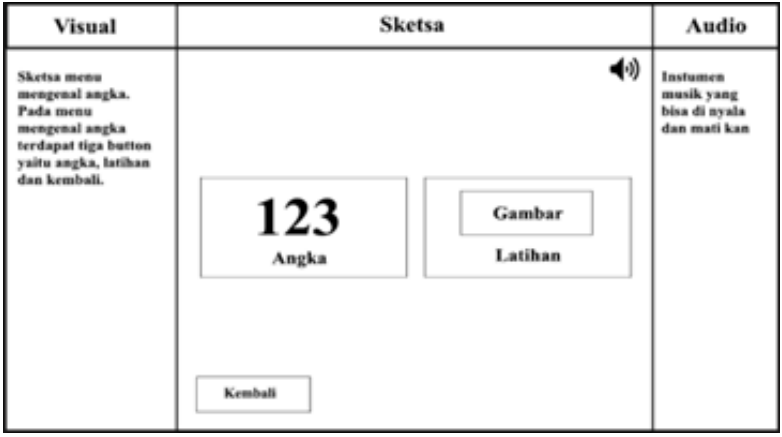

Gambar 5. Desain Halaman Menu Mengenal Angka 


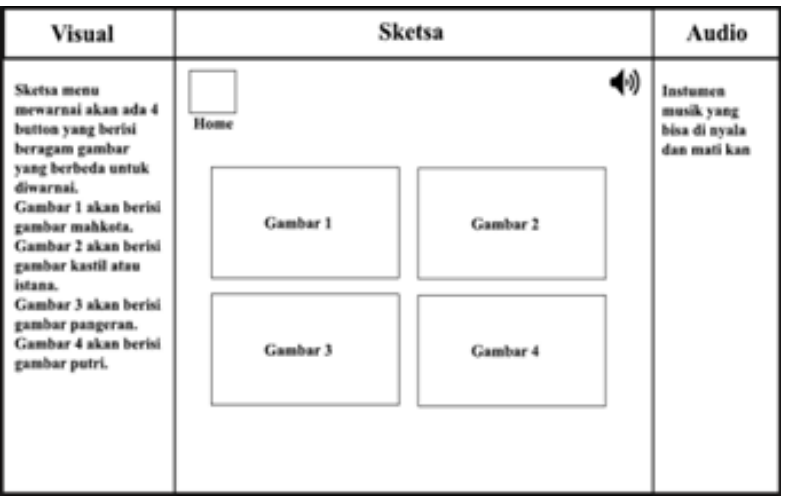

Gambar 6. Desain Halaman Menu Mewarnai

\section{Pengumpulan bahan (Material collecting)}

Pada tahap ini dilakukan pengumpulan bahan yang terakait dengan materi pembelajaran. Bahanbahan pembelajaran didapatkan dengan melakukan studi pustaka yang diperoleh artikel atau jurnal ilmiah dari internet. Bahan-bahan yang dikumpulkan yang terkait dengan pembuatan aplikasi seperti gambar, animasi, dan audio. Bahan-bahan tersebut didapatkan secara gratis dari internet. Kemudian, gambar dan animasi yang telah dikumpulkan akan di modifikasi dengan menggunakan Adobe Photoshop CC 2017. Audio yang berupa backsound anak-anak didapatkan secara gratis dari internet dan audio lainnya berupa audio untuk perintah dan petunjuk aplikasi dengan menggunakan suara anakanak yang direkam sendiri.

\section{Pembuatan (Assembly)}

Tahap ini adalah hasil implementasi dari proses perancangan yang telah dilakukan sebelumnya. Perangkat lunak yang digunakan dalam membuat media pembelajaran adalah adobe flash CS6. Hampir setiap animasi dalam aplikasi ini berisikan suara dan setiap halaman pada aplikasi ini berisi musik yang dapat menarik perhatian anak. Berikut ini adalah sebagian tampilan antarmuka aplikasi mendia pembelajaran untuk anak tunagrahita.

\section{a. Halaman utama}

Pada halaman utama berisi button mengenal angka, mengenal huruf, mengenal benda, mewarnai dan keluar dari aplikasi. Di halaman ini juga terdapat button petunjuk penggunaan di pojok kanan atas untuk para guru dan orang tua.

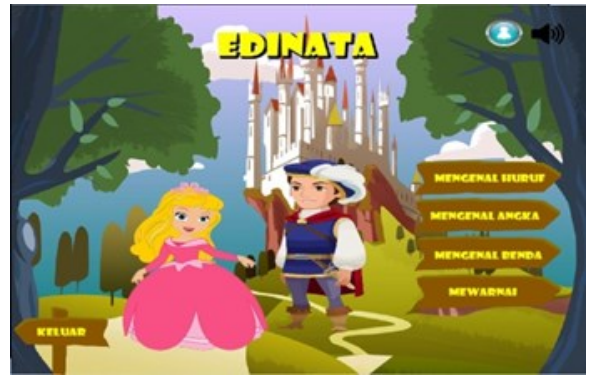

Gambar 7. Tampilan halaman utama

b. Halaman mengenal huruf

Pada halaman ini anak akan belajar mengenal huruf yang dikemas dengan animasi yang menarik. Tidak hanya mengenal, anak juga akan diajari cara mengeja kata. Setelah itu, anak bisa berlatih materi yang diajarkan dengan bermain game. Pada game mengenal huruf, anak akan diminta mencari suatu huruf diantara huruf huruf lain.

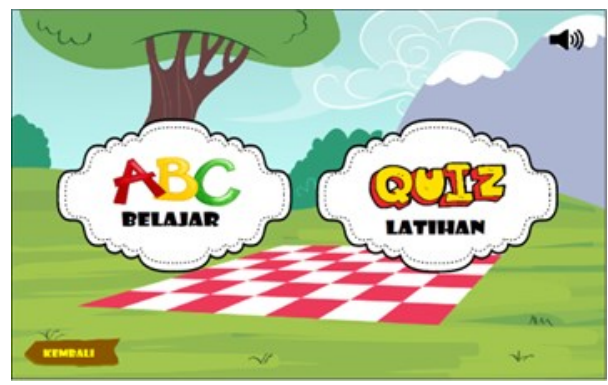

Gambar 8. Tampilan menu mengenal huruf

\section{c. Halaman mengenal angka}

Pada halaman ini anak akan belajar mengenal angka dari nol hingga sepuluh. Setelah itu, anak bisa berlatih materi yang diajarkan dengan bermain game. Pada game mengenal angka, anak akan diminta menghitung jumlah suatu benda.

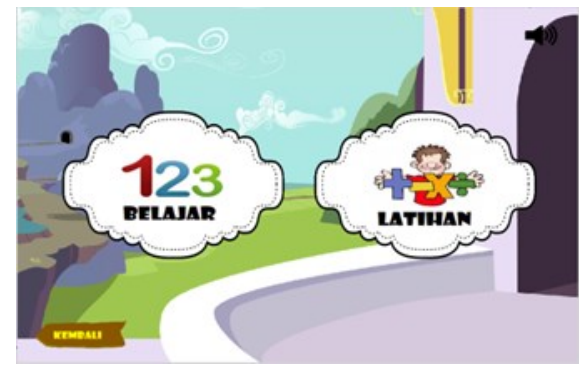

Gambar 9. Tampilan menu mengenal angka 


\section{d. Halaman mengenal benda}

Pada halaman ini anak diajarkan mengenal nama benda benda yang ada di sekitar mereka. Diantaranya di kamar mandi, dapur, kamar tidur, dan di kelas. Setelah itu, anak diminta latihan dengan menyebutkan nama dari suatu benda yang tadi sudah di pelajari. Pada game puzzle, benda benda yang di pelajari sebelumnya dibuat puzzle dan anak diminta untuk menyatukan kepingan puzzle.

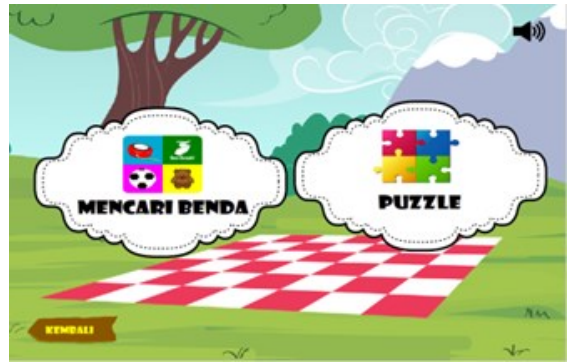

Gambar 10. Tampilan menu mengenal benda

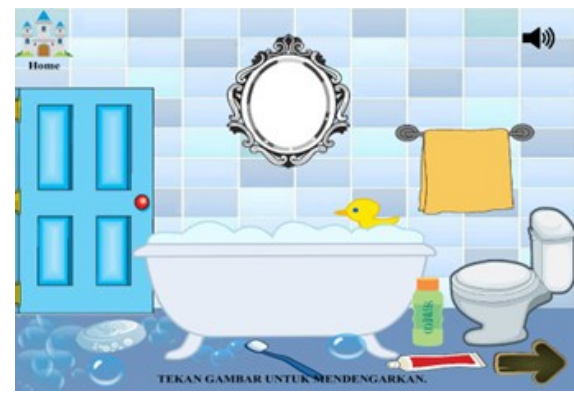

Gambar 11. Tampilan menu mencari benda

\section{e. Halaman mewarnai}

Pada halaman mewarnai, anak akan diajarkan mengenal warna dan melatih kreatifitasnya dalam mewarnai.

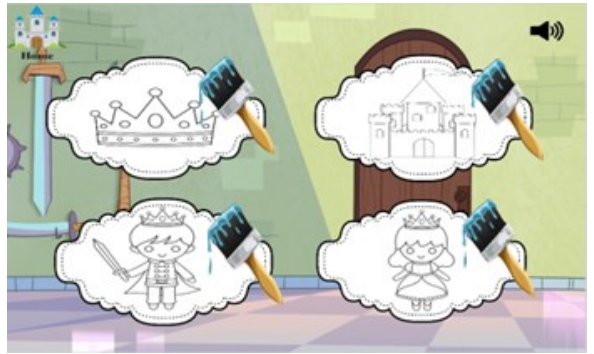

Gambar 12. Tampilan menu mewarnai

\section{Pengujian (Testing)}

Setelah aplikasi berhasil dijalankan, pengujian perlu dilakukan untuk memastikan aplikasi berfungsi dengan benar. Pengujian yang digunakan dalam menguji aplikasi ini adalah pengujian black box. Berikut ini adalah hasil dari pengujian aplikasi.

Tabel 1. Pengujian Black box

\begin{tabular}{|c|c|c|c|}
\hline Input & Proses & Output & Hasil \\
\hline $\begin{array}{l}\text { Mem- } \\
\text { buka } \\
\text { Aplikasi }\end{array}$ & $\begin{array}{c}\text { Menampilkan } \\
\text { animasi loading }\end{array}$ & $\begin{array}{l}\text { Animasi } \\
\text { loading }\end{array}$ & Sesuai \\
\hline $\begin{array}{l}\text { Tombol } \\
\text { Suara }\end{array}$ & $\begin{array}{c}\text { Menghi-dupkan/ } \\
\text { Mematikan } \\
\text { backsound }\end{array}$ & $\begin{array}{l}\text { Suara back } \\
\text {-sound } \\
\text { hidup/ } \\
\text { mati }\end{array}$ & Sesuai \\
\hline $\begin{array}{l}\text { Tombol } \\
\text { Mengena } \\
\text { I Huruf }\end{array}$ & $\begin{array}{c}\text { Menampilkan } \\
\text { halaman menu } \\
\text { mengenal huruf }\end{array}$ & $\begin{array}{l}\text { Halaman } \\
\text { mengenal } \\
\text { huruf }\end{array}$ & Sesuai \\
\hline $\begin{array}{c}\text { Tombol } \\
\text { ABC Bela- } \\
\text { jar }\end{array}$ & $\begin{array}{c}\text { Menampilkan } \\
\text { halaman ABC } \\
\text { belajar }\end{array}$ & $\begin{array}{c}\text { Halaman } \\
\text { ABC belajar }\end{array}$ & Sesuai \\
\hline $\begin{array}{l}\text { Tombol } \\
\text { Quiz Lati- } \\
\text { han }\end{array}$ & $\begin{array}{c}\text { Menampilkan } \\
\text { halaman quiz } \\
\text { latihan }\end{array}$ & $\begin{array}{c}\text { Halaman } \\
\text { quiz latihan }\end{array}$ & Sesuai \\
\hline $\begin{array}{l}\text { Tombol } \\
\text { Mengena } \\
\text { I Angka }\end{array}$ & $\begin{array}{c}\text { Menampilkan } \\
\text { halaman menu } \\
\text { mengenal angka }\end{array}$ & $\begin{array}{l}\text { Halaman } \\
\text { mengenal } \\
\text { angka }\end{array}$ & Sesuai \\
\hline $\begin{array}{c}\text { Tombol } \\
123 \text { Bela- } \\
\text { jar }\end{array}$ & $\begin{array}{l}\text { Menampilkan } \\
\text { halaman menu } \\
123 \text { belajar }\end{array}$ & $\begin{array}{c}\text { Halaman } \\
123 \text { belajar }\end{array}$ & Sesuai \\
\hline $\begin{array}{l}\text { Tombol } \\
\text { Latihan }\end{array}$ & $\begin{array}{l}\text { Menampilkan } \\
\text { halaman menu } \\
\text { latihan }\end{array}$ & $\begin{array}{c}\text { Halaman } \\
\text { latihan }\end{array}$ & Sesuai \\
\hline $\begin{array}{l}\text { Tombol } \\
\text { Mengena } \\
\text { I Benda }\end{array}$ & $\begin{array}{l}\text { Menampilkan } \\
\text { halaman menu } \\
\text { mengenal ben- } \\
\text { da }\end{array}$ & $\begin{array}{l}\text { Halaman } \\
\text { mengenal } \\
\text { benda }\end{array}$ & Sesuai \\
\hline $\begin{array}{l}\text { Tombol } \\
\text { Mencari } \\
\text { Benda }\end{array}$ & $\begin{array}{l}\text { Menampilkan } \\
\text { halaman menu } \\
\text { mencari Benda }\end{array}$ & $\begin{array}{c}\text { Halaman } \\
\text { mencari } \\
\text { benda }\end{array}$ & Sesuai \\
\hline $\begin{array}{l}\text { Tombol } \\
\text { Puzzle }\end{array}$ & $\begin{array}{c}\text { Menam-pilkan } \\
\text { halaman menu } \\
\text { puzzle }\end{array}$ & $\begin{array}{c}\text { Halaman } \\
\text { puzzle }\end{array}$ & Sesuai \\
\hline $\begin{array}{l}\text { Tombol } \\
\text { Mewar- } \\
\text { na }\end{array}$ & $\begin{array}{l}\text { Menampilkan } \\
\text { halaman menu } \\
\text { mewarnai }\end{array}$ & $\begin{array}{l}\text { Halaman } \\
\text { mewarnai }\end{array}$ & Sesuai \\
\hline $\begin{array}{l}\text { Tombol } \\
\text { Keluar }\end{array}$ & $\begin{array}{l}\text { Menutup ap- } \\
\text { likasi }\end{array}$ & $\begin{array}{c}\text { Keluar dari } \\
\text { aplikasi }\end{array}$ & Sesuai \\
\hline
\end{tabular}

Pada tahap pengujian, dilakuan pegujian black box untuk semua fungsi yang terdapat pada Aplikasi Edinata. Berdasarkan pengujian yang telah dilakukan, dapat disimpulkan bahwa semua menu 
yang terdapat pada aplikasi sesuai dengan yang diharapkan dan dapat berjalan dengan baik.

\section{Distribusi (Distribution)}

Tahap distribusi merupakan tahap dimana aplikasi disimpan dalam suatu media penyimpanan. Seperti hardisk dan CD yang sebelumnya sudah dijadikan file autoplay. Ini merupakan tahap akhir dimana media (dalam bentuk CD) telah siap untuk dioperasikan maupun digandakan untuk dipublikasikan. Aplikasi media pembelajaran untuk anak tunagrahita ini dibuat menggunakan Adobe Flash Professional CS6. Setelah aplikasi selesai dibuat, aplikasi di-export menjadi file dalam format.exe, agar aplikasi tersebut dapat dijalankan dengan mudah di perangkat komputer.

\section{KESIMPULAN}

Berdasarkan hasil penelitian, maka disimpulkan bahwa penelitian ini menghasilkan sebuah aplikasi media pembelajaran berbasis multimedia interaktif untuk anak tunagrahita ringan yang dinamakan Aplikasi Edinata. Pada pengujian black box dilakukan pengujian pada setiap fungsionalitas dari menu yang terdapat pada aplikasi. Berdasarkan pengujian black box setiap menu pada aplikasi dapat dijalankan dengan baik. Diharapkan dengan adanya aplikasi ini, dapat menjadi alternatif sebagai media pembelajaran untuk anak tunagrahita dalam mengenal huruf, angka, dan benda sehingga proses pembelajaran dapat lebih mudah dilakukan.

\section{DAFTAR PUSTAKA}

[1] F. F. C. Triara Puspitasari, Boko Susillo, “Implementasi Metode Dempster-Shafer Dalam Sistem Pakar Diagnosa Anak Tunagrahita Berbasis Web," J. IIm. Tek. Inform., vol. 4, no. 1, pp. 1-13, 2016.

[2] F. Y. Al Irsyadi and Y. S. Nugroho, "Game Edukasi Pengenalan Anggota Tubuh Dan Pengenalan Angka Untuk Anak Berkebutuhan Khusus (ABK) Tunagrahita Berbasis Kinect," Pros. SNATIF, vol. 2, pp. 1-8, 2015.

[3] R. A. Trisnawati, "Aplikasi Multimedia Sebagai Media Pembelajaran Mengenal Bilangan Untuk Anak Tunagrahita," Universitas Negeri Semarang, 2019.
[4] F. R. Arfani, "Pengaruh Penggunaan Multimedia Interaktif Berbasis Adobe Flash Terhadap Peningkatan Prestasi Belajar Tema 5 Anak Tunagrahita Ringan Kelas 5 Di SLB Negeri Surakarta Tahun Pelajaran 2016/2017," IJDS Indones. J. Disabil. Stud., vol. 4, no. 1, pp. 1-8, 2017, doi: 10.21776/ ub.ijds.2017.004.01.1.

[5] I. Umaya, "Pengembangan Media Pembelajaran Matematika Untuk Meningkatkan Konsentrasi Minat Belajar Siswa Tunagrahita," Univ. Nusant. PGRI Kediri, vol. 1, no. April, pp. 1-7, 2017.

[6] I. Binanto, "Analisa Metode Classic Life Cycle ( Waterfall ) Untuk Pengembangan Perangkat Lunak Multimedia," in Jurnal Universitas Sanata Dharma Yogyakarta, 2014, no. MAY 2014, pp. 1-6, doi: 10.13140/2.1.1586.4968.

[7] S. L. Rahayu, U. P. Utama, J. S. Informasi, and G. D. Document, "Rancang Bangun Aplikasi Game Edukasi," J. Komput. dan Inform., vol. 15, no. 1, pp. 1-8, 2012.

[8] F. Y. Al Irsyadi, S. L. M. Sholihah, and E. Sudarmilah, "Game Edukasi Merawat Diri Untuk Anak Tunagrahita Tingkat Sekolah Dasar Berbasis Kinect Xbox 360," Simetris J. Tek. Mesin, Elektro dan IImu Komput., vol. 7, no. 2, pp. 693-700, 2016, doi: 10.24176/ simet.v7i2.783.

[9] A. Putri, F. Yanta, and J. Efendi, “Efektivitas Media Pop-Up Book Untuk Meningkatkan Kemampuan Mengenal Huruf Vokal Bagi Anak Tunagrahita Ringan," J. Multidicsiplinary Res. Dev., vol. 2, no. 2, pp. 44-50, 2020.

[10] N. L. G. K. Widiastuti and I. M. A. Winaya, "Prinsip Khusus Dan Jenis Layanan Pendidikan Bagi Anak Tunagrahita," J. Santiaji Pendidik., vol. 9, no. 2, pp. 116-126, 2019, doi: 10.36733/jsp.v9i2.392.

[11] A. R. Dewi, R. R. Isnanto, and K. T. Martono, “Aplikasi Multimedia sebagai Media Pembelajaran IImu Pengetahuan Sosial Materi Budaya di Indonesia menggunakan Unity Engine untuk Sekolah Dasar," J. Teknol. dan Sist. Komput., vol. 3, no. 4, p. 471, 2015, doi: 10.14710/jtsiskom.3.4.2015.471-480. 
[12] A. Nastiti, R. R. Isnanto, and K. T. Martono, "Aplikasi Multimedia sebagai Media Pembelajaran Sejarah Indonesia Masa Perjuangan Kemerdekaan Untuk Sekolah Dasar Berbasis Android," J. Teknol. dan Sist. Komput., vol. 3, no. 4, p. 512, 2015, doi: 10.14710/jtsiskom.3.4.2015.512-522.

[13] S. Herman, S. Samsuni, and F. Fathurohman, "Pengembangan Sistem Membaca Al-Qur'an Dengan Metode Multimedia Development Life Cycle," Ilk. J. Ilm., vol. 11, no. 2, pp. 95-101, 2019, doi: 10.33096/ilkom.v11i2.406.95101.
[14] Siti Nurajizah, “Implementasi Multimedia Development Life Cycle Pada Aplikasi Pengenalan Lagu Anak-Anak Berbasis Multimedia," J. PROSISKO, vol. Vol. 3 No., no. 2, p. 6, 2016.

[15] I. M. S. Ardana, "Pengujian Software Menggunakan Metode Boundary Value Analysis dan Decision Table Testing," J. Teknol. Inf. ESIT, vol. 14, no. 11, pp. 40-47, 2019. 